\title{
PENINGKATAN HASIL BELAJAR IPS DENGAN MODEL PROBLEM SOLVING BERBANTUAN MEDIA GAMBAR
}

\author{
Fitria Novita Sarie* ，Sukiman** ， dan Ika Oktavianti** \\ *) Prodi Pendidikan Dasar, Fakultas Pascasarjana, Universitas Negeri Semarang \\ **) Dosen Progdi PGSD, FKIP, Universitas Muria Kudus \\ e-mail: sariefitria@yahoo.co.id; Telp: +6285712873592
}

\begin{abstract}
Before this research is implemented, the results of the fifth grade social studies students is low. This is because the model is still the conventional learning, the students just listen to the material without any direct learning experience. Problem Solving Model emphasizes student activity by utilizing the real environment developed as a learning medium. Picture selected as a learning medium because it is universal, not bound by the limitations of language. The conditions pretest showed only $50 \%$ of students who reach the KKM, with an average value of class 73,5. PTK results showed an increase in the skills of teachers, student activities, and student learning outcomes in social studies. In the first cycle mean the percentage of teachers' skills $80 \%$ with either category, increased by $7 \%$ in the second cycle as much as $87 \%$ with very good category. The percentage of student activity first cycle as much as $78 \%$ in both categories increased $13 \%$ in the second cycle as much as $91 \%$ in the excellent category. Student learning outcomes first cycle reaches 75\% (9 of 12 students achieving KKM) in both categories, increased $16,7 \%$ to $91,7 \%$ (11 of 12 students achieving KKM) in the excellent category, while the indicator of success is $75 \%$ of students reach KKM.
\end{abstract}

\begin{abstract}
ABSTRAK
Sebelum PTK ini dilaksanakan, hasil belajar IPS siswa kelas V rendah. Kondisi ini disebabkan karena model pembelajaran masih konvensional, siswa hanya mendengarkan materi tanpa ada pengalaman belajar secara langsung. Model Problem Solving menekankan aktivitas siswa dengan memanfaatkan lingkungan sekitar yang nyata sebagai media pembelajaran yang dikembangkan. Gambar dipilih sebagai media pembelajaran karena sifatnya universal, tidak terikat oleh keterbatasan bahasa. Kondisi awal pretes menunjukkan hanya 50\% siswa yang mencapai KKM, dengan nilai rata-rata kelas 73,5. Hasil PTK menunjukan adanya peningkatan keterampilan guru, aktivitas siswa, dan hasil belajar siswa pada mata pelajaran IPS. Siklus I rerata persentase keterampilan guru $80 \%$ dengan kategori baik, meningkat $7 \%$ pada siklus II sebanyak 87\% dengan kategori sangat baik. Persentase aktivitas siswa siklus I sebanyak $78 \%$ dalam kategori baik meningkat $13 \%$ pada siklus II sebanyak $91 \%$ dalam kategori sangat baik. Hasil belajar siswa siklus I mencapai 75\% (9 dari 12 siswa mencapai KKM) dalam kategori baik, meningkat 16,7\% menjadi 91,7\% (11 dari 12 siswa mencapai KKM) dalam kategori sangat baik, sedangkan indikator keberhasilannya adalah $75 \%$ siswa mencapai KKM.
\end{abstract}

Kata kunci: Problem Solving, Media Gambar 


\section{PENDAHULUAN}

Kondisi awal pembelajaran IPS di SD 2 Tanjungkarang menunjukkan guru kurang melibatkan siswa secara aktif, guru tidak melakukan variasi pembelajaran serta tidak menggunakan media pembelajaran. Hal ini menyebabkan minat dan motivasi belajar siswa rendah yang berdampak pula pada rendahnya hasil belajar IPS. Kondisi seperti ini dapat diperbaiki dengan menerapkan model pembelajaran yang lebih baik sehingga dapat meningkatkan kualitas kegiatan belajar mengajar.

Model Problem Solving digunakan dalam pembelajaran untuk melibatkan siswa secara aktif, melatih siswa berfikir kritis, dan mampu menyelesaikan masalah secara ilmiah (Suprayogi, 2011: 64). Dengan penggunaan model pembelajaran yang tepat akan menghidupkan pembelajaran yang ditandai dengan siswa aktif, kreatif, dan menyenangkan. Media gambar digunakan untuk membantu guru dalam menyampaikan materi pelajaran sehingga lebih mudah diterima oleh siswa Solihatin (2008: 27). Media gambar sifatnya universal, mudah dimengerti, dan tidak terikat oleh keterbatasan bahasa. Gambar yang berwarna-warni diharapkan dapat membangkitkan semangat dan motivasi siswa dalam belajar sehingga materi yang disampaikan dapat diingat. Hasil belajar diperoleh sebagai hasil dari pembelajaran Ilmu Pengetahuan Sosial yang telah dilakukan (Hartiny, 2010: 33). Hasil belajar ditinjau dari klasifikasi Benyamin Bloom yang meliputi tiga ranah, yakni kognitif, afektif, dan psikomotoris.

Untuk penelitian lebih lanjut pada model problem solving, sangat penting untuk mengetahui bagaimana langkahlangkah pembelajaran yang digunakan untuk dapat meningkatkan hasil belajar
IPS siswa. Sebagian besar studi tentang Penerapan Model Problem Solving menunjukkan adanya peningkatan aktivitas dan hasil belajar siswa.

Artikel ini melaporkan kajian Peningkatan Hasil Belajar IPS Dengan Model Problem Solving Berbantuan Media Gambar.

\section{Metode Penelitian}

Tujuan utama PTK adalah untuk memperbaiki dan memberi variasi pengajaran guru serta meningkatkan aktivitas belajar siswa di kelas. Penelitian ini berupaya memperoleh pembelajaran IPS dari keterampilan guru menerapkan model problem solving dan aktivitas siswa yang diteliti yang bertujuan untuk meningkatkan hasil belajar IPS pada siswa kelas V SD 2 Tanjungkarang Kudus.

Penelitian dilaksanakan dua siklus, tiap siklus melalui 4 tahapan yaitu perencanaan, pelaksanaan, observasi dan refleksi. Subjek penelitian adalah peneliti sebagai guru dan siswa kelas V. Teknik pengumpulan data yang digunakan adalah observasi, tes dan dokumentasi. Tes yang dimaksud dalam penelitian disini yaitu postest yang dilakukan untuk mengukur kemampuan siswa setelah pembelajaran. Observasi digunakan untuk mengamati keterampilan guru dalam mengajar dengan menerapkan model problem solving dan aktivitas siswa menggunakan instrumen berupa check list. Dokumentasi digunakan untuk memperoleh data dalam bentuk foto-foto bukti penelitian. Tes validitas instrument menggunakan teknik korelasi product moment angka kasar dan tes reliabilitas menggunakan Metode Belah Dua dengan rumus Sperman Brown. Instrumen juga dianalisis Tingkat Kesukaran Soal dan Daya Bedanya.

\section{Hasil dan Pembahasan}


Hasil penelitian tindakan kelas dengan menggunakan Model Problem Solving berbantuan media gambar pada pembelajaran IPS kelas V di SD 2 Tanjungkarang menunjukkan terjadi peningkatan hasil belajar dari niali kognitif pretes. Hasil belajar siswa dalam mengerjakan soal pretest sebelum diadakan tindakan dapat dilihat pada tabel 1.

Tabel 1. Rekapitulasi Nilai Pretest Siswa Kelas V SDN 2 Tanjungkarang

\begin{tabular}{llc}
\hline No. & Uraian & Keterangan \\
\hline 1. & Kriteria ketuntasan minimum (KKM) IPS & 70 \\
2. & Nilai Tertinggi & 93 \\
3. & Nilai Terendah & 47 \\
4. & Rata-Rata Kelas & 73,5 \\
5. & Siswa yang mencapai KKM & 6 \\
6. & Siswa yang tidak mencapai KKM & 6 \\
7. & Ketuntasan Klasikal Hasil Belajar & $50 \%$ \\
\hline
\end{tabular}

Data diatas menunjukkan hasil belajar IPS di kelas V belum maksimal. Permasalahan yang ditemukan terkait dengan keterampilan guru dalam mengajar IPS, yaitu: (1) terlalu cepat memberi apersepsi sehingga kurang mengena dengan materi; (2)penyampaian materi kurang jelas; (3)kurang memberikan pertanyaan pada siswa; (4)Proses pembelajaran IPS masih berpusat pada guru. Permasalahan dari siswa kelas V SDN 2 Tanjungkarang terkait dengan aktivitas Diagram 1. Peningkatan Keterampilan Guru Siklus I dan Siklus II siswa dalam pembelajaran, yaitu; (1) belum mencapai nilai KKM yang di tentukan yaitu $\leq 70(50 \%$, yaitu 6 dari 12 siswa belum mencapai KKM); (2) kurang aktif dalam pembelajaran; (3) Sebagian siswa merasa jenuh dengan model pembelajaran yang dilaksanakan.

Setelah dilakukan perbaikan pada siklus I dan II terjadi peningkatan Keterampilan Mengajar Guru. Hasil pengamatan tersebut dinyatakan dengan persentase dalam diagram 1 .

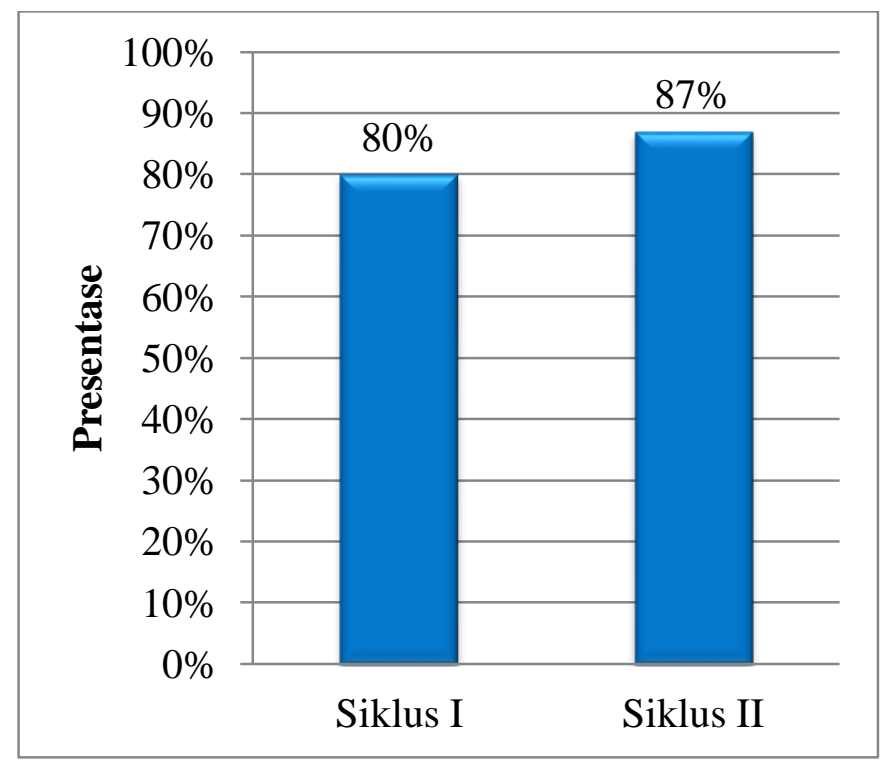


Terjadi peningkatan keterampilan guru sebesar $7 \%$ dari siklus I ke siklus II. Pada siklus I guru telah mampu membangkitkan minat dan partisipasi aktif siswa di dalam kelas, akan tetapi pemberian apersepsi terlalu cepat. Pada siklus
II guru telah mampu melaksanakan 9 keterampilan mengajar dengan baik. Peningkatan ketrampilan guru memberi dampak terhadap aktivitas siswa. Hasil pengamatan aktifitas siswa siklus I dan II dinyatakan dengan persentase dalam diagram 2.

Diagram 2. Peningkatan Aktivitas Siswa Siklus I dan Siklus II

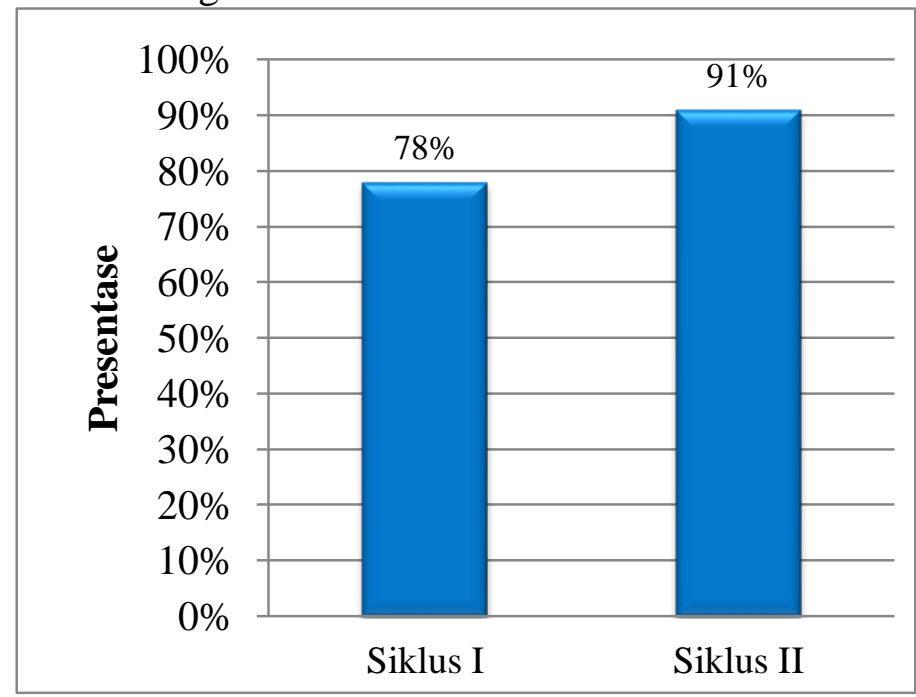

Terjadi peningkatan aktivitas siswa sebesar $13 \%$ dari siklus I. Pada siklus I siswa mulai aktif bertanya dan menyampaikan pendapat, akan tetapi masih ada siswa yang diam. Pada siklus II terlihat semangat siswa yang tinggi terhadap pelajaran, siswa telah mampu menyelesaikan permasalahan dan mampu bekerjasama dengan kelompoknya. Peningkatan keterampilan guru dan aktivitas siswa dalam pembelajaran, menyebabkan peningkatan pula pada hasil belajar siswa, yang dinyatakan dengan persentase dalam diagram 3.

Diagram 3. Peningkatan Ketuntasan Klasikal Hasil Belajar Siswa Siklus I dan Siklus II

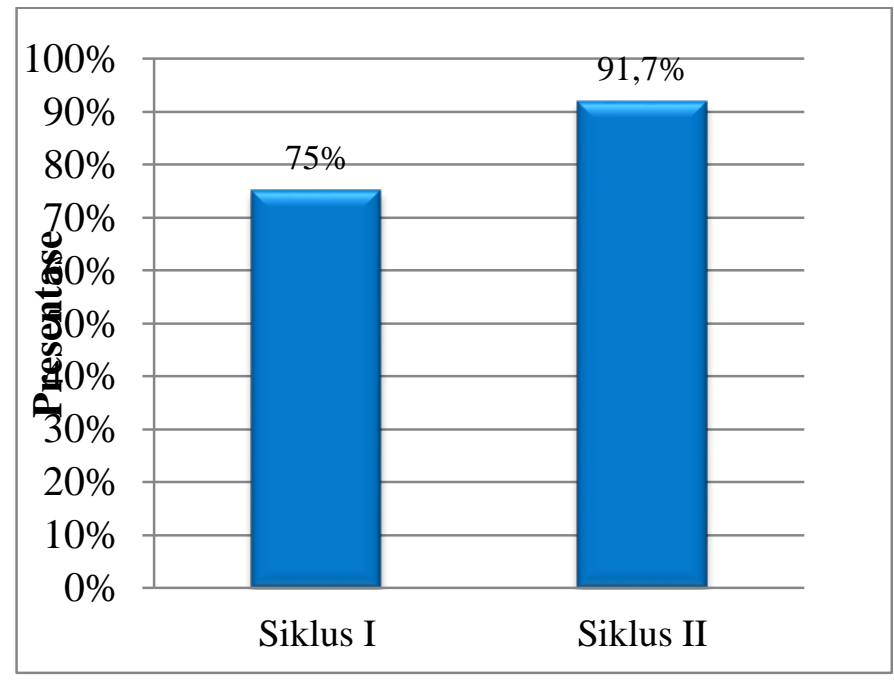


Terjadi peningkatan Ketuntasan Klasikal Hasil Belajar Siswa sebesar $16,7 \%$ dari Siklus I ke Siklus II. Pada siklus I 9 dari 12 siswa mencapai KKM dalam kategori baik. Setelah diadakan perbaikan siklus II, sebanyak 11 dari 12 siswa mencapai KKM dalam kategori sangat baik.

Penelitian yang dilakukan oleh Erwin Putera Permana tahun 2011 memaparkan penggunaan model problem solving berpengaruh terhadap hasil pembelajaran siswa. Pembelajaran dengan menggunakan model pembelajaran Problem Solving berbantuan media gambar membuat siswa terlibat dalam pembelajaran secara langsung yang menyenangkan. Siswa berlatih untuk berpikir kritis dan kreatif untuk memecahkan masalah yang ada dalam kehidupan sehari-hari. Oleh sebab itu, siswa sangat antusias untuk mengikuti kegiatan pembelajaran.

\section{SIMPULAN}

Pembelajaran IPS melalui model Problem Solving berbantuan media gambar dapat meningkatkan hasil belajar siswa. Saran dalam penelitian ini, guru dapat menerapkan model
Siswa diharapkan mampu mengaplikasikan pengetahuan yang diperoleh untuk mengatasi masalahmasalah yang muncul dalam kehidupan sehari-hari melalui model pembelajaran Problem Solving. Kegiatan ini dilakukan secara berkelompok sehingga melatih siswa untuk dapat bekerjasama dengan temannya. Melalui model pembelajaran Problem Solving, guru menjadi lebih kreatif karena harus dapat memilih masalah-masalah yang muncul dalam kehidupan sehari- hari dan bagaimana mencari alternatif pemecahan masalah tersebut. Jadi guru tidak lagi banyak berceramah dan menjadi pusat pembelajaran, melainkan melibatkan siswa secara langsung untuk mendapatkan pengetahuannya itu sehingga pembelajaran menjadi lebih bermakna.

Problem Solving dalam kegiatan pembelajaran di kelas agar pelaksanaan pembelajaran lebih bermakna, aktivitas siswa meningkat, sehingga dapat meningkatkan hasil belajar IPS.

\section{Ucapan Terima Kasih}

Penulis menyampaikan terikma kasih kepada Sekolah Dasar Negeri 2 Tanjungkarang atas bantuannya dalam penelitian. Penulis juga menyampaikan terima kasih kepada Universitas Muria Kudus atas dukungannya pada penelitian ini.

\section{DAFTAR PUSTAKA}

Ahmadi, Abu. (2007). Sosiologi Pembelajaran. Jakarta: Rineka Cipta

Akbar, Sa'dun. Hadi Sriwiyana. (2010). Pengembangan Kurikulum dan Pembelajaran Ilmu Pengetahuan Sosial (IPS). Yogyakarta: Cipta Media

Anitah W, Sri. (2009). Strategi Pembelajaran di SD. Jakarta: Universitas Terbuka.

Arikunto, Suharsimi, dkk. (2008). Penelitian Tindakan Kelas. Jakarta: Bumi Aksara (2009). Dasar-Dasar Evaluasi Pembelajaran. Jakarta: Bumi Aksara 
Aqib, Zainal. (2011). Penelitian Tindakan Kelas untuk Guru SD, SLB, dan TK. Bandung: Yrama Widya

Aziz Wahab, Abdul. dkk. (2009a). Konsep Dasar IPS. Jakarta: Universitas Terbuka (2009b). Metode dan Model-model mengajar Ilmu Pengetahuan Sosial (IPS). Bandung: Alfabeta

Baharuddin, Esa Nur Wahyuni. (2010). Teori Belajar dan Pembelajaran. Yogyakarta: Ar-Ruzz Media.

Dimyati, Mudjiono. (2009). Belajar dan Pembelajaran. Jakarta: Rineka Cipta.

Djamarah, Syaiful Bahri. (2008). Psikologi Belajar. Jakarta: PT Rineka Karya.

Fathoni, Abdurrahmat. (2005). Antropologi Sosial Budaya. Jakarta:Rineka Cipta

Gunawan, Rudy. (2011). Pembelajaran IPS Filosofi, Konsep, dan Aplikasi. Bandung: Alfabeta.

Hamid, Akib. (2007). Statistika Dasar. Jakarta: Universitas Terbuka.

Hartiny, Rosma. (2010). Model Penelitian Tindakan Kelas. Yogyakarta: Teras

Hasibuan, J. J. (2009). Proses Belajar Mengajar. Bandung: Rosdakarya.

Hidayati dkk. (2008). Pengembangan Pembelajaran IPS SD. Dirjendikti Depdiknas.

Keraf, Gorys. (2004). Komposisi. Semarang: Bina Putera

Khoiru Ahmadi, Iif. sofan Amri. (2011). Mengembangkan Pembelajaran IPS Terpadu. Jakarta: Prestasi Pustakaraya

Koentjaraningrat. (1983). Kebudayaan Mentalitas dan Pembangunan. Jakarta: Gramedia

KTSP. (2006). Standar Isi dan Standar Kompetensi Kelulusan Untuk Satuan Pembelajaran Dasar SD/MI. Jakarta: BP Cipta Jaya.

Mulyasa, E. (2009). Kurikulum Tingkat Satuan Dasar. Bandung: PT Remaja Rosdakarya.

Musfiqon. (2012). Pengembangan Media dan Sumber Pembelajaran. Jakarta: Prestasi Pustaka

Permana, Erwin Putera. (2011). Meningkatkan Hasil Belajar Melalui Metode Problem Solving dalam Pembelajaran IPS Kelas IV SDN KONTES 01 Kecamatan Gandusari Kabupaten Blitar. Skripsi. Malang. UM.

Poerwanti, Endang. dkk. (2008). Asesmen Pembelajaran SD. Direktorat Jenderal

Pembelajaran Tinggi, Departemen Pembelajaran Nasional.

Purwanto. (2013). Evaluasi Hasil Belajar. Yogyakarta: Pustaka Belajar.

Ratnasari. (2010). Keterampilan Guru. Artikel. Dapat diakses di http://ratnasari.student.fkip.uns.ac.id/. Diunduh pada tanggal 21 Agustus 2013

Erdian, Lelia Vika. (2011). Model Pembelajaran Problem Solving dengan Menggunakan Media Gambar untuk Meningkatkan Kualitas Pembelajaran IPS di Kelas IV SDN Gunungpati 02 Kota Semarang. Skripsi. Semarang. UNNES. 
Sardiman. (2011). Interaksi dan Motivasi Belajar-Mengajar. Jakarta: Rajawali Pers.

Sapriya. (2011). Pembelajaran IPS. Bandung: Remaja Rosdakarya

Santyasa, I Wayan. (2007). Metodologi Penelitian Tindakan Kelas. Dapat diakses di http://www.freewebs.com. Diunduh pada 25 Juli 2013

Slameto. (2010). Belajar dan Faktor-faktor Yang Mempengaruhinya. Jakarta: Rineka Cipta

Solihatin, Etin, Raharjo. (2008). Cooperatif Learning Analisis Model Pembelajaran IPS. Jakarta: Bumi Aksara

Sudjana, Nana. (2012). Penilaian Hasil Proses Belajar Mengajar. Bandung: Remaja Rosdakarya

Sugiyanto. (2010). Model-model Pembelajaran Inovatif. Surakarta: Yuma Pustaka

Suprayogi. dkk. (2011). Pembelajaran Ilmu Pengetahuan Sosial. Semarang: Widya Karya

Suprijono, Agus. (2012). Cooperative Learning Teori dan Aplikasi Paikem. Yogyakarta: Pustaka Pelajar

Sukardi. (2009). Metodologi Penelitian Pembelajaran. Jakarta: Bumi Aksara

Tahnia, Ayu. dkk. (2011). Model Pemecahan Masalah dalam Pembelajaran IPS di Sekolah Dasar. Artikel. Jurnal Sekolah Dasar: Kajian teori dan Praktik Pembelajaran Vol.20. No.2. November 2011. Hlm. 150-158

Trianto. (2011). Model-Model Pembelajaran Inovatif Berorientasi Konstruktivistik. Jakarta: Prestasi Pustaka Publisher

. . . . (2009). Mendesain Model Pembelajaran Inovatif Progresif: Konsep, Landasan, dan Implementasinya pada Kurikulum Tingkat Satuan Pembelajaran (KTSP). Jakarta: Kencana

Wardhani, I.G.A.K dkk. (2007). Penelitian Tindakan Kelas. Jakarta: UniversitasTerbuka.

Wena, Made. (2009). Strategi Pembelajaran Inovatif Kontemporer. Jakarta: BumiAksara.

Winataputra, Udin S. (2008). Teori Belajar dan Pembelajaran. Jakarta: Universitas Terbuka. 